\title{
HOLIMO II: a digital holographic instrument for ground-based in situ observations of microphysical properties of mixed-phase clouds
}

\author{
J. Henneberger ${ }^{1}$, J. P. Fugal ${ }^{2}$, O. Stetzer ${ }^{1}$, and U. Lohmann ${ }^{1}$ \\ ${ }^{1}$ ETH Zurich, Institute for Atmospheric and Climate Science, Universitaetsstrasse 16, 8092 Zurich, Switzerland \\ ${ }^{2}$ Johannes Gutenberg-Universität Mainz, Institute for Atmospheric Physics, J.-J.-Becherweg 21, 55099 Mainz, Germany \\ Correspondence to: J. Henneberger (jan.henneberger@env.ethz.ch)
}

Received: 25 March 2013 - Published in Atmos. Meas. Tech. Discuss.: 13 May 2013

Revised: 25 September 2013 - Accepted: 4 October 2013 - Published: 6 November 2013

\begin{abstract}
Measurements of the microphysical properties of mixed-phase clouds with high spatial resolution are important to understand the processes inside these clouds. This work describes the design and characterization of the newly developed ground-based field instrument HOLIMO II (HOLographic Imager for Microscopic Objects II). HOLIMO II uses digital in-line holography to in situ image cloud particles in a well-defined sample volume. By an automated algorithm, two-dimensional images of single cloud particles between 6 and $250 \mu \mathrm{m}$ in diameter are obtained and the size spectrum, the concentration and water content of clouds are calculated. By testing the sizing algorithm with monosized beads a systematic overestimation near the resolution limit was found, which has been used to correct the measurements.

Field measurements from the high altitude research station Jungfraujoch, Switzerland, are presented. The measured number size distributions are in good agreement with parallel measurements by a fog monitor (FM-100, DMT, Boulder USA). The field data shows that HOLIMO II is capable of measuring the number size distribution with a high spatial resolution and determines ice crystal shape, thus providing a method of quantifying variations in microphysical properties. A case study over a period of $8 \mathrm{~h}$ has been analyzed, exploring the transition from a liquid to a mixed-phase cloud, which is the longest observation of a cloud with a holographic device. During the measurement period, the cloud does not completely glaciate, contradicting earlier assumptions of the dominance of the Wegener-Bergeron-Findeisen (WBF) process.
\end{abstract}

\section{Introduction}

Mixed-phase clouds, containing a mixture of water vapor, liquid droplets and ice crystals, are frequently observed in the atmosphere (e.g., Shupe et al., 2008). Liquid droplets and ice crystals inside mixed-phase clouds differ in size, concentration and shape; typically, the water droplets are smaller ( 5 to $25 \mu \mathrm{m}$ ) and more numerous (a few hundred per $\mathrm{cm}^{3}$ ) compared to the ice crystals ( $>30 \mu \mathrm{m}$, a few per liter) (e.g., McFarquhar et al., 2007). As an atmospheric mixture of ice crystals and water droplets is thermodynamically unstable, mixed-phase clouds are not in equilibrium. Depending on the vertical velocity, particles of both phases may grow; ice particles may grow at the expense of liquid droplets in the so-called Wegener-Bergeron-Findeisen (WBF) process (Wegener, 1911; Bergeron, 1935; Findeisen, 1938); or particles of both phases may evaporate (Korolev, 2007). The rate of such processes depends on the spatial scale, at which the phase composition of cloud changes, which can be less than the resolution of cloud instrumentation (Vidaurre and Hallett, 2009). For a thorough understanding of the observed longevity of mixed-phase clouds, and an accurate representation in models, measurements of cloud particle size and phase distributions are crucial (Baumgardner et al., 2012). Instruments capable of such measurements over a wide range of particle sizes and at high spatial resolution are therefore essential.

Holography offers the possibility to simultaneously detect the position of numerous particles in a well-defined sample volume and to obtain intensity and phase images of these 
particles. From these images, the size and shape of individual cloud particles can be obtained through image analysis.

In comparison to other commonly used in situ techniques which measure single cloud particles, holography has specific advantages and disadvantages (see Baumgardner et al., 2011, for an overview). Because a real image is captured, in holography no assumption concerning the shape, orientation or refractive index of a particle has to be made, unlike in light scattering instruments, for example, the Forward Scattering Spectrometer Probe (FSSP, PMS Inc., Boulder USA). On the other hand, with scattering techniques cloud particles down to $1 \mu \mathrm{m}$ can be observed, whereas in holography the resolving power limits the lower bound of size measurements to a few $\mu \mathrm{m}$. Compared to other imaging techniques, such as triggered particle imaging, holography provides a well-defined detection volume. Triggered particle imagers, like the Cloud Particle Imager (CPI, SPECinc, Colorado USA), yield uncertainties in the estimation of the effective sample volume (Baum et al., 2005).

The digital holographic method has already been used in atmospheric science in some instruments, starting with a prototype instrument (Lawson and Cormack, 1995), airborne measurements (HOLODEC, Fugal et al., 2004; HOLODEC2, Spuler and Fugal, 2011), ground-based measurements (Raupach et al., 2006), and also lab measurements with HOLIMO I (HOLographic Imager for Microscopic Objects I, Amsler et al., 2009), the predecessor of HOLIMO II. Many of these instrument projects showed promising results, but have not been continued, likely because of the time and effort needed for the complex data analysis. This analysis entails a computationally expensive hologram reconstruction and image-analysis of typically terabytes of data (representing millions of particles). However, with the progress of computer technology, the cost and time required for such a task have become more economical. In particular, the large number of parallel processors in modern graphics processing units can be exploited to expedite reconstruction. But the most important progress is that a software package, HOLOSUITE (based on Fugal et al., 2009) is now available, which automates the data processing. The software is shared and developed by different groups working with holographic instruments (HOLODEC 2, Fugal and Shaw, 2009; GIPFELHOLO).

In this paper we present the newly developed instrument HOLIMO II, designed for ground-based field measurements. Ground-based measurements benefit from an orderof-magnitude lower inlet velocity in comparison to airborne measurements, which reduces ice crystal shattering on the inlet and increases the spatial resolution with which cloud properties can be measured.

The paper is structured as follows. First, we describe the working principles of digital in-line holography (Sect. 2.1), the instrument parameters (Sect. 2.2) and a correction of the inlet sampling efficiency for nonisokinetic effects (Sect. 2.3). Second, we briefly summarize
Table 1. HOLIMO II instrument parameters.

\begin{tabular}{|c|c|c|}
\hline Laser wavelength $(\lambda)$ & \multicolumn{2}{|l|}{$532 \mathrm{~nm}$} \\
\hline Sampling velocity $(U)$ & \multicolumn{2}{|l|}{$0.37 \mathrm{~ms}^{-1}$} \\
\hline Size range $\left(d_{p}\right)$ & \multicolumn{2}{|l|}{$6-250 \mu \mathrm{m}$} \\
\hline \multirow[t]{2}{*}{ Camera frame rate } & $15 \mathrm{~s}^{-1}$ & \\
\hline & original & $2 \times 2$ binning \\
\hline Camera pixel number & $8.2 \times 10^{6}$ & $2.1 \times 10^{6}$ \\
\hline Effective pixel size $\left(D_{\text {pixel,obj }}\right)$ & $1.36 \mu \mathrm{m}$ & $2.72 \mu \mathrm{m}$ \\
\hline Optical field of view & \multicolumn{2}{|c|}{$4.53 \mathrm{~mm} \times 3.41 \mathrm{~mm}$} \\
\hline Sample volume dimension & \multicolumn{2}{|l|}{$0.25 \mathrm{~cm}^{3}$} \\
\hline Sample volume rate & \multicolumn{2}{|c|}{$3.8 \mathrm{~cm}^{3} \mathrm{~s}^{-1}$} \\
\hline Smallest detectable feature & \multicolumn{2}{|l|}{$3.4 \mu \mathrm{m}$} \\
\hline
\end{tabular}

the hologram reconstruction particle identification and sizing algorithm (Sect. 3.1), and show calibration measurements with monodispersed beads (Sect. 3.2) to test for accuracy and precision of the measurements. Finally, we present data collected at the high altitude research station Jungfraujoch (Switzerland) during measurement campaigns in January and April 2012 (Sect. 4.1). The size distribution of three case-study periods are compared to a Fog Monitor (FM-100, DMT, Boulder USA) (Sect. 4.2). We show the development of the microphysical properties of a cloud over an eight hour period (Sect. 4.3). This is, to our knowledge, the longest observation of a cloud by a holographic instrument.

\section{Instrument characterization}

HOLIMO II creates images of single particles using digital in-line holography. It is a stand-alone, remote controllable field instrument capable of in situ size distribution measurements for cloud particles between 6 and $250 \mu \mathrm{m}$ with high temporal resolution (on the order of seconds, depending on particle concentrations). A summary of the instrument parameters is given in Table 1.

\subsection{Working principle}

The setup for digital in-line holography is quite simple (Fig. 1). In principle, only a coherent light source and a digital camera are needed. Holography is a two step process: first, the interference pattern of a reference and scattered wave are recorded as the hologram; second, the image is reconstructed. In digital holography, a digital camera records the hologram and the reconstruction is done numerically by a computer algorithm.

In conventional imaging, sharp images are only obtained for objects placed in the object plane. Objects outside the object plane, or, more specifically, outside the depth of field, yield a blurred image. In holography, the interference pattern from objects outside the object plane are recorded and sharp 


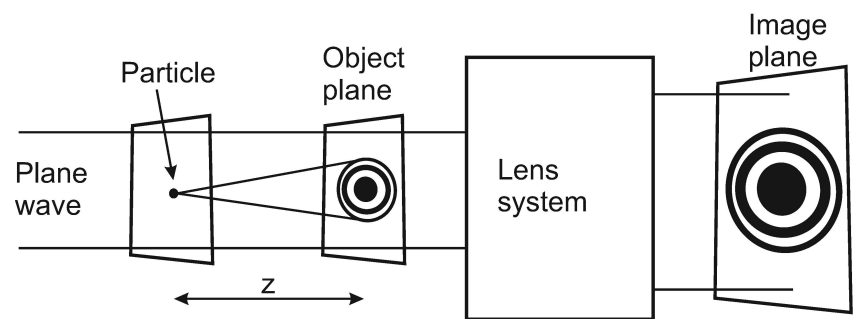

Fig. 1. Working principle of HOLIMO II: a plane reference wave illuminates a particle. The reference wave and the scattered wave interfere and form a interference pattern (e.g., the hologram) at a distance $z$. The lens system magnifies the hologram from the object plane to the image plane where the camera is located.

images for every transversal plane at longitudinal distance $z$ can be obtained.

When using a digital camera for image capture, the quite coarse pixels limit the achievable resolution. To overcome this restriction a magnification is needed. One possibility for magnification is digital in-line holographic microscopy (DIHM) (Jericho et al., 2006) with a divergent laser beam as the light source, as was done in HOLIMO I (Amsler et al., 2009). The achievable magnification is not theoretically limited, and resolutions on the order of the laser wavelength have been achieved (Garcia-Sucerquia et al., 2006). However, DIHM is associated with a decrease in detection volume. In addition, in DIHM the magnification and the resolution depends on the distance of an object to the camera and therefore the detection volume is difficult to quantify, complicating concentration measurements. As the predecessor of the present instrument (HOLIMO I) had such a geometry (Amsler et al., 2009), the achieved detection volume was only $8.3 \mathrm{~mm}^{3}$.

HOLIMO II avoids the detection-volume complications of DIHM by using a collimated laser beam. Therefore, the detection volume is simply the field of view of the camera times the reconstruction interval. Magnification is achieved using a lens system in front of the camera itself. A telecentric lens design is employed, to avoid positional errors in magnification and to minimize distortion (Spuler and Fugal, 2011; Lan and Lin, 2009).

\subsection{Description of the instrument}

The instrument consists of a control box and an inlet box. To allow for field measurements in rough conditions, like those at Jungfraujoch (cf. Sect. 4.1), parts are sealed inside temperature-stabilized, water-tight boxes. The control box houses the power supplies, the temperature controller, the laser, and the central computer used to control the instrument and record the data. Inside the inlet box, the optical system, a blower, and a mass flow meter are placed (Fig. 2). The inlet tip and the windows are actively heated to prevent icing.
In contrast to other holographic instruments (Fugal and Shaw, 2009; Raupach et al., 2006), which are designed with an open path configuration, HOLIMO II samples air through a circular inlet with a diameter of $50 \mathrm{~mm}$. Although this leads to anisokinetic sampling effects (see Sect. 2.3) and may modify the local spatial-structure of the cloud particles, the sampling inlet allows for a simplified construction and sampling even at very calm conditions (since the sample flow is controlled by the blower). Because any sampling geometry has an effect on the free flow, the best approach, in our belief, is to use a well-characterized geometry. For the thin-walled circular inlet used by HOLIMO II, corrections for anisokinetic sampling have already been developed (Baron and Willeke, 2005).

During field measurements, changes in wind direction may cause impaction of large particles onto the HOLIMO II inlet walls. To avoid this, HOLIMO II is mounted on a twoaxis rotor. The rotor allows for $360^{\circ}$ rotation in the horizontal plane, and $\pm 45^{\circ}$ in the vertical. The alignment with the ambient wind field allows the use of iso-axial inlet-efficiency corrections described in Sect. 2.3. Laminar flow inside the inlet pipe is ensured by setting the flow speed to $U=0.37 \mathrm{~m} \mathrm{~s}^{-1}$.

The laser (FDSS532-Q2, CryLaS, Germany) emits pulses at $532 \mathrm{~nm}$ with a pulse length of $1 \mathrm{~ns}$, short enough to prevent motion blur of the sample particles. The laser head is placed inside the temperature-stabilized control box. The emitted light is transported to the inlet through a single-mode fiber. Although about $40 \%$ of the laser power is lost, using a fiber cleans the laser profile because only the lowest transverse electromagnetic mode (TEM00) is transmitted. After exiting the fiber, the laser beam is collimated to a diameter of $16 \mathrm{~mm}$. The imaging system includes a telecentric lens (TZL 0494/4.0, Sill Optics, Germany) with a four times magnification and a numerical aperture $\mathrm{NA}_{\text {lens }}=0.125$. The $\mathrm{CCD}$ camera (SVS8050, SVS-VISTEK, Germany) can take 15 images per second and has $3320 \times 2496,5.5 \mu \mathrm{m}$ pixels.

The optical setup inside the inlet is located on the horizontal center plane. To prevent double images, the object plane of the optical system is located outside the detection volume (inside the second window encountered by the laser light). Longitudinally, the detection volume is limited by the two windows, which have an inner spacing of $44 \mathrm{~mm}$; transversally, the detection volume is limited by the field of view of the imaging system: $4.53 \mathrm{~mm} \times 3.41 \mathrm{~mm}$. The beam diameter of the laser is chosen to be much larger than the field of view of the image system, so that the detection volume is illuminated by the center portion of the Gaussian beam profile.

The optical resolution of this system was tested using a US Air Force (1951 USAF) high resolution target, as detailed in Appendix A. For reconstructions at distance $z<20 \mathrm{~mm}$ an optical resolution of $6.8 \mu \mathrm{m}$ was determined. To avoid edge effects, we neglected particles within a $3 \%$ border $(50$ pixels) of the detector boundaries. HOLIMO II therefore has a usable detection volume of $0.25 \mathrm{~cm}^{3}$ per frame. This 


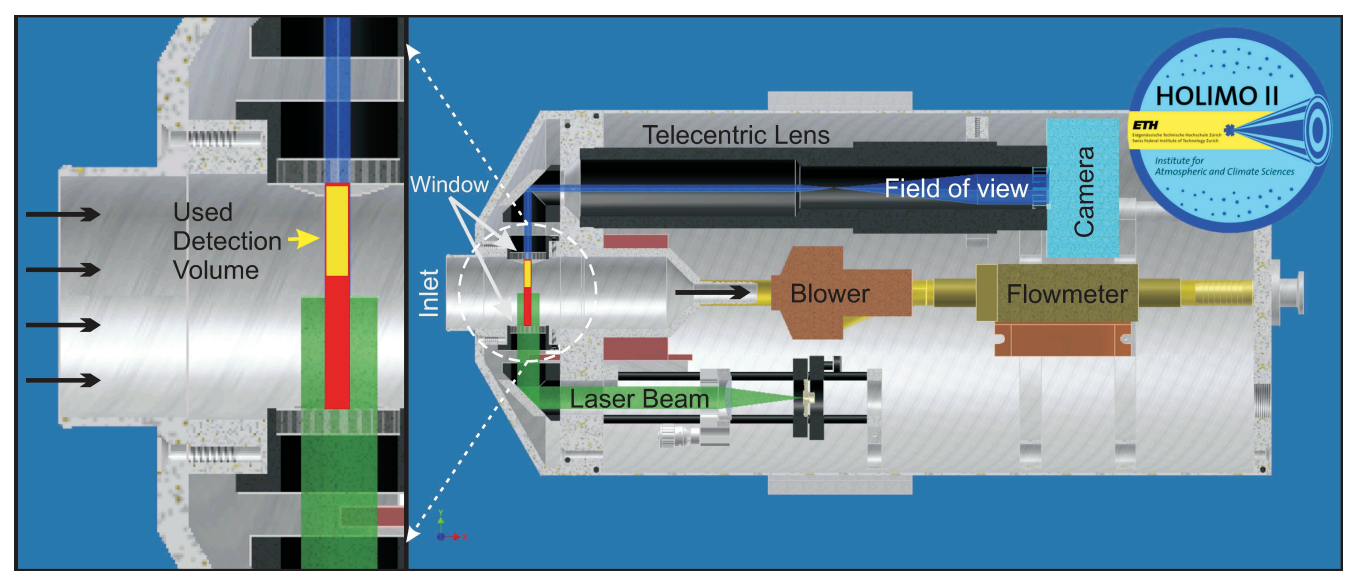

Fig. 2. A horizontal cross section of the HOLIMO II inlet box, showing the major components. The inlet tip is magnified in a blowup (left panel). Particles are drawn in through the inlet (from the left) by a blower (in the center) to scatter light from the laser beam (green). The detection volume (red and yellow) is limited by the field of view of the optical system (blue) and the two windows (top and bottom edges of red region). For measurements, only that part of the detection volume where the highest resolution could be achieved was used (yellow).

corresponds to $3.8 \mathrm{~cm}^{3} \mathrm{~s}^{-1}$, in which the smallest detectable feature is $3.4 \mu \mathrm{m}$.

\subsection{Inlet efficiency correction}

Any inlet-using instrument must address the problem that the measured concentrations inside the instrument are not the same as the free-volume concentrations outside. When the ambient flow velocity $U_{0}$ is higher than the HOLIMO II sampling velocity $U=0.37 \mathrm{~m} \mathrm{~s}^{-1}$, sub-isokinetic sampling $\left(U_{0} / U>1\right)$ cannot be avoided. In a sub-isokinetic flow, incoming large aerosol particles will be enriched inside the inlet, when their inertia prevents them from following the ambient flow around the instrument.

The relative change is described by the inlet efficiency $\eta_{\text {inlet }}$, which is comprised of two components: first, the efficiency with aerosol particles enter the inlet, described by the aspiration efficiency $\eta_{\text {asp }}$; second, the efficiency with which particles are transmitted from inlet to detection volume, described by the transportation efficiency $\eta_{\text {trans }}$ (Baron and Willeke, 2005). The total inlet efficiency is then the product of both

$\eta_{\text {inlet }}=\eta_{\text {asp }} \cdot \eta_{\text {trans }}$.

We accounted for this effect by using a aspiration efficiency, which is also valid for large sub-isokinetic values $\left(U_{0} / U \leq 50\right)$ (Paik and Vincent, 2002)

$\eta_{\mathrm{asp}}=1+\left(\frac{U_{0}}{U}-1\right)\left(1-\frac{1}{1+k_{2} \mathrm{Stk}}\right)$

with $k_{2}=2+0.617 \frac{U}{U_{0}}-0.9\left(\frac{U_{0}}{U}\right)^{0.1}$ and the Stokes number Stk $=\left(d_{\mathrm{p}}^{2} \rho U_{0}\right) /\left(18 \eta d_{i}\right)$, where $d_{\mathrm{p}}$ is the particle, $d_{i}$ the inlet diameter, $\rho$ the particle density and $\eta$ the viscosity of air.
We accounted for decreased transmission efficiency $\eta_{\text {trans }}$ due to inertial wall losses in the inlet using (Liu et al., 1989)

$\eta_{\text {trans }}=\frac{1+\left(\frac{U_{0}}{U}-1\right) /\left(1+\frac{2.66}{\text { Stk }^{2 / 3}}\right)}{1+\left(\frac{U_{0}}{U}-1\right) /\left(1+\frac{0.418}{\text { Stk }}\right)}$

assuming all particles hitting the wall are lost. We did not account for gravitational losses, because the inlet velocity $U$ is high enough and therefore particles which are reaching the detection volume, which lies vertically in the middle of the pipe and axially $50 \mathrm{~mm}$ behind the inlet, are not influenced by gravitational settling to the walls. The total inlet efficiency $\eta_{\text {inlet }}$ is shown in Fig. 3c. In particular, it shows that particles larger than $10 \mu \mathrm{m}$ are enriched under sub-isokinetic sampling.

To confirm that this formula can also be used for the nonideal thin-walled HOLIMO II inlet, we simulated the air and particle flow towards the inlet with a computational fluid dynamics (CFD) program (FLUENT/ANSYS). For the simulation, the turbulence model without gravity was used. A constant wind field was applied isoaxial to the geometry of the inlet. The hydrometeors were represented by spherical particles with no interaction with the continuous phase, and all particles which hit the wall were trapped. These assumptions have some uncertainties. Not all particles will be lost to the wall, but larger droplets might splash and larger ice crystals might shatter into pieces. The magnitude of the overestimation of the number of smaller particles is hard to quantify. However, because of the low inlet velocities, particularly in comparison to airborne measurements, it is expected to not significantly change the results.

The simulations were performed for 1,5 and $10 \mathrm{~ms}^{-1}$ ambient wind velocities (Fig. 3). Although deviations occur, particularly for particles larger than $30 \mu \mathrm{m}$, the simulated 

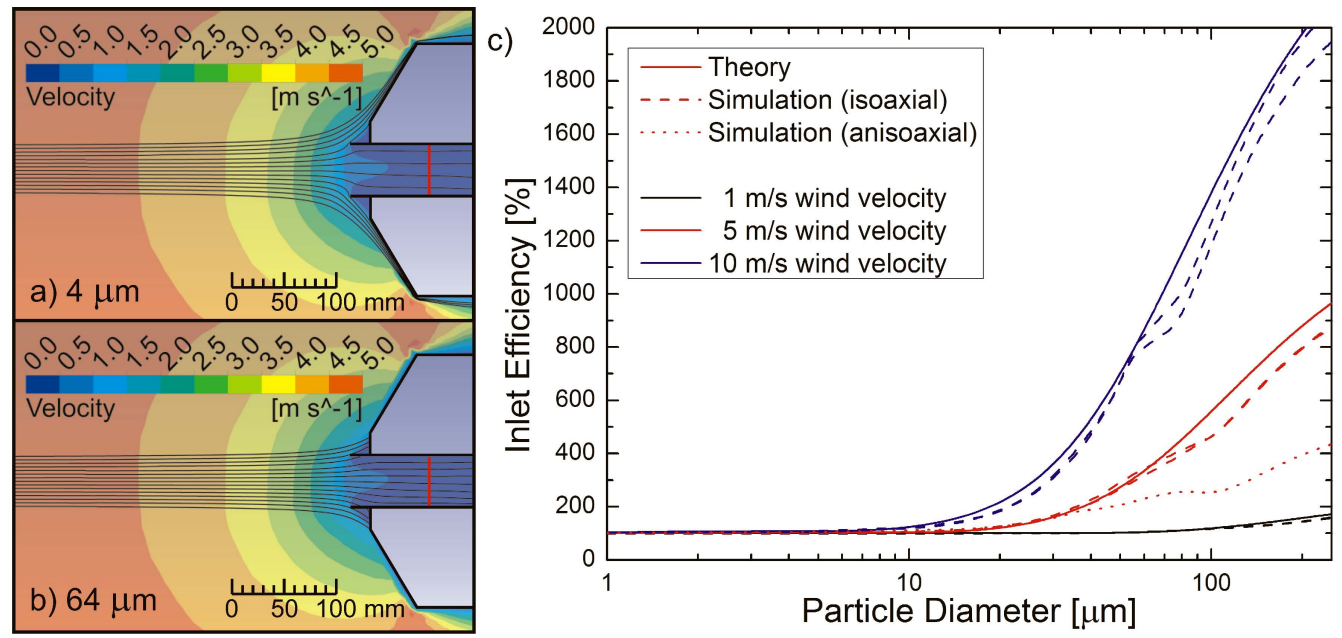

Fig. 3. Simulations of the HOLIMO II inlet. Particle sampling for (a) $4 \mu \mathrm{m}$ and (b) $64 \mu \mathrm{m}$ diameter spheres was simulated in a $5 \mathrm{~ms} \mathrm{~s}^{-1}$ ambient wind field. The detection plane is indicated by a red line in (a) and (b). In both cases, wind deceleration begins $20 \mathrm{~cm}$ ahead of the inlet tip. Due to inertia, the larger particles in (b) deviate from the air flow around the inlet and become enriched in the sample volume. The (c) simulated (dashed lines, multiple runs) and theoretical (solid lines, Paik and Vincent, 2002; Liu et al., 1989) results are compared for three different wind velocities. An additional simulation (red dotted line) is shown for anisoaxial sampling of $15^{\circ}$ for a wind velocity $5 \mathrm{~ms} \mathrm{~s}^{-1}$.

inlet efficiencies are in good agreement with the analytical formulas. Hence, simultaneously measured wind velocities were used to correct the measured concentrations by applying the inlet efficiency formula (Eq. 1).

An additional simulation using $15^{\circ}$ anisoaxial sampling was performed to represent a sampling scenario where the HOLIMO II inlet is not facing into the wind. The results of this simulation (Fig. 3c, red dotted line) show that particularly particles larger than $30 \mu \mathrm{m}$ are undersampled. Anisoaxial sampling should therefore be avoided by aligning the inlet to the ambient wind field. Finally, because all the simulations and theories assume spherical particles, measurements of ice crystals, which usually are not spherical, are likely subjected to additional uncertainty.

\section{Data analysis and calibration measurements}

\subsection{Description of the algorithm}

After recording hundreds of thousands of holograms, an automated algorithm is needed for reconstruction and characterization of the particles. We used the software package HOLOSUITE, published under the GNU General Public License, whose algorithms are described in detail in Fugal et al. (2009). In this section, we give a summary of this algorithm and describe the modifications we implemented.

Before processing, the holograms were divided by the pixel-by-pixel median of seven adjacent holograms to reduce noise and stationary signals (e.g., dirt on the optics). The reconstruction uses the filtering form of the Huygens-Fresnel kernel, and produces sharp (or on-focus) images of planes perpendicular to the optical axes, at a given reconstruction distance $z$. For each hologram, 460 planes were reconstructed, each separated by $50 \mu \mathrm{m}$. The volume is partitioned in discrete volume elements, called voxels, defined by the pixel aperture and the distance between the layers.

In longitudinal direction the reconstruction volume was exceeded by an additional $2 \mathrm{~mm}$ buffer zone to reduce false detection of particles behind the border of the detection volume. The reconstruction step takes most of the computation time and thus was accelerated by using a graphics processing unit (GPU). A low-pass filter was applied to ensure a comparable resolution in the whole detection volume.

Particles were distinguished from background noise by binarizing the reconstructed voxels using a global threshold in both the intensity and phase amplitudes. The value of the thresholds was determined manually, ensuring that particles, in particular the small ones, were detected and noise was not significantly contributed to false detections. Particle-containing voxels were identified by dilating the binarized voxels by a fixed number, then grouping adjacent voxels together (so-called connected component labeling, Haralick and Shapiro, 1992). The grouped voxels represent a probable particle. The dilated particle is normally cigarshaped; in transversal direction it exceeds the real particle only marginally, but, on the contrary, the extension in the longitudinal direction can reach a few $\mathrm{mm}$, because the blurred images from a particle in an adjacent plane may be detected.

To find the real $z$ position of a particle, a trace needed to be defined. We identified the plane containing the in-focus particle with an edge detection by deriving the Sobel gradient of the phase of the reconstructed image at each plane, then taking the per-pixel standard deviation of each Sobelfiltered plane Fugal et al. (2009). As the standard deviation 


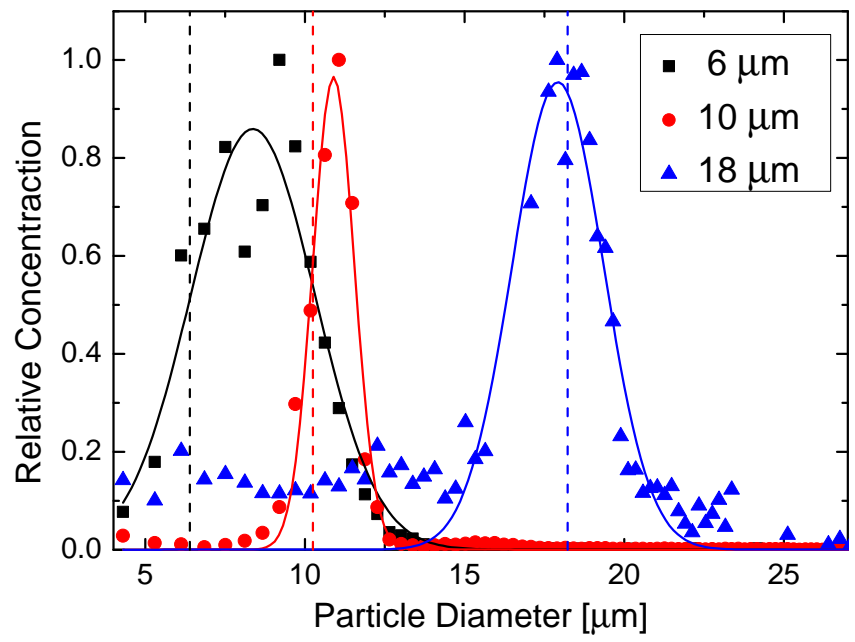

Fig. 4. Size spectra of monodisperse polystyrene latex spheres with diameters of $6.4,10.3$ and $18.2 \mu \mathrm{m}$ measured by HOLIMO II. For each size, a Gaussian distribution was fitted (solid lines) through the normalized measurements (points) and compared to the nominal size (dashed line).

is a measure of extreme values, the plane with the maximum standard deviation presumably has the highest Sobel gradients, or the sharpest edges.

Particles at the edge of reconstructed holograms appear distorted, because their signal is only partially recorded. To avoid counting these distorted particles, we excluded particles in the outer three percent of the transversal detection volume, and at the first millimeter in the longitudinal detection volume.

Another possible source of noise is the out-of-focus fringes surrounding the real particle which sometimes can be strong enough to exceed the thresholds and, consequently, to be detected as particles themselves. Such noise could be excluded by tightening the binarization threshold, but this would lower overall detection efficiency, especially for particles close to the detection limit (e.g., far away and/or small particles). Another approach could be an increase of the dilation size, so that artifacts are grouped with real particles. However, this could render real particles inside the dilation volume undetectable. Rather, to avoid these false particles, we excluded all smaller particles within in a cylindrical volume around the larger particle. Because the size and intensity of these interference fringes increases with the size of the particles, we scaled the diameter of the cylinder with the diameter of the particles. Because the cloud particles are quite diluted, this excluded less than $0.5 \%$ of the volume.

Particle size was estimated by counting the pixels in the focal plane which are over the binarization threshold and calculating an equivalent diameter of a sphere of the same size $(\mathrm{Lu}$ et al., 2008). To estimate particle concentration, the measurement volume is needed, which, fortunately, is well defined in holography and is independent of the sampling speed, as long
Table 2. Comparison of the sizing of monodisperse polystyrene latex spheres. The standard deviation of the APS and HOLIMO II measurements were derived by a Gaussian fit to the normalized data. Multisizer data were provided by the manufacturer.

\begin{tabular}{llll}
\hline \multicolumn{4}{c}{ Particle diameter $[\mu \mathrm{m}]$} \\
\hline Multisizer & $6.40 \pm 0.11$ & $10.25 \pm 0.19$ & $18.23 \pm 0.24$ \\
APS & $6.61 \pm 0.28$ & $10.47 \pm 0.64$ & - \\
HOLIMO II & $8.4 \pm 1.9$ & $10.9 \pm 0.6$ & $18.0 \pm 1.4$ \\
\hline
\end{tabular}

as adjacent images do not overlap. To account for the enrichment of larger particles the measured concentrations were corrected by the inlet efficiency. Water content was calculated assuming particles were composed of pure water, with density $\rho=1000 \mathrm{~kg} \mathrm{~m}^{-3}$.

For all calculations only particles between $6 \mu \mathrm{m}$ and $250 \mu \mathrm{m}$ were taken into account. Below the lower limit, which is equal to the smallest size we used for calibration, sizing becomes imprecise and the detection efficiency of the algorithm decreases. Particles above the upper limit located at the edge of the detection volume might be detected only partially and can partly shadow the detection volume. Therefore all holograms with particles larger than $250 \mu \mathrm{m}$ were removed from the data analysis. The upper limit is not a theoretical upper limit, and could be increased in future algorithm versions.

\subsection{Size calibrations}

The sizing algorithm of HOLIMO II was tested with monodisperse spheres of diameters of $6.4,10.3$ and $18.2 \mu \mathrm{m}$. We focused on measuring these small diameters near the resolution limit, because for larger diameters an accuracy within $10 \%$ relative deviation was already confirmed ( $\mathrm{Lu}$ et al., 2008).

The particles used were cross-linked poly(methyl methacrylate) (PMMA) spheres (colloquial acrylic glass), with a density of $\rho=1180 \mathrm{~kg} \mathrm{~m}^{-3}$. The particle diameter of the samples was accurately measured by the manufacturer (Microbeads, Norway) with a COULTER Multisizer 3. The particles were suspended in air using a Fluidized Bed Aerosol Generator (TSI, Minnesota USA) and the size distributions were measured by an Aerodynamic Particle Sizer (APS, TSI) and HOLIMO II. However, the $18.2 \mu \mathrm{m}$ particles were too large to be reliably counted by the APS. The measured size distributions were normalized to their maxima, and the mean diameter and standard deviation of a Gaussian fit computed (Fig. 4). The obtained particle diameters from all three instruments are summarized in Table 2. For the two smaller samples, the APS measurements agree with the manufacturer-reported values within the uncertainty. The $18.2 \mu \mathrm{m}$ spheres experiment had a low signal-to-noise ratio, because these large particles were more difficult to suspend 


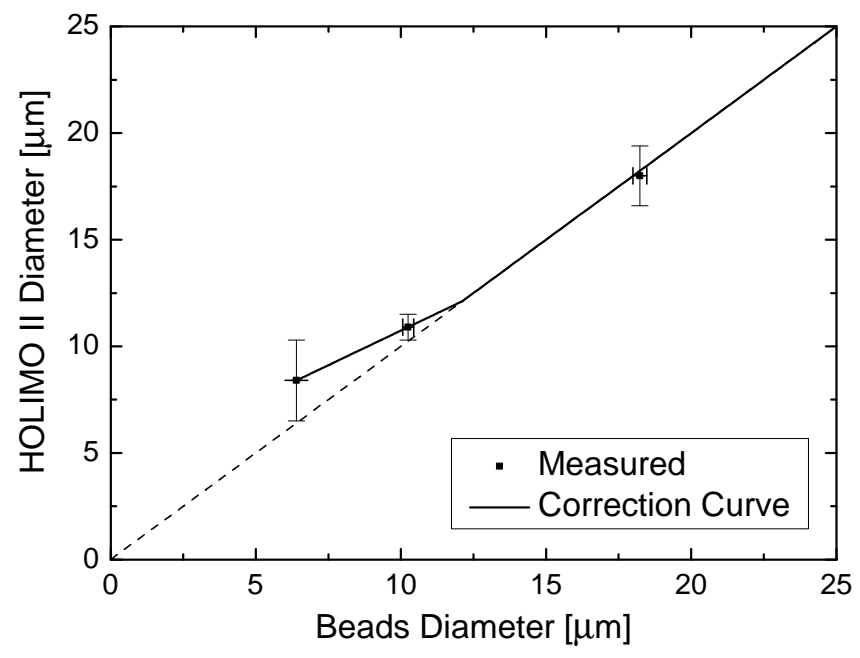

Fig. 5. HOLIMO II size measurements versus the accurate (manufacturer-supplied) sizes of monodispersed spheres and the correction curve applied to HOLIMO II data.

in the air, resulting in nonzero concentrations outside the Gaussian distribution.

For the two larger diameters, the HOLIMO II algorithm measurements agreed with the sphere diameter with an accuracy less than the square root of the pixel size $(\sqrt{2.72 \mu \mathrm{m}}=$ $1.65 \mu \mathrm{m})$. For larger diameters a similar accuracy of this algorithm was already confirmed (Lu et al., 2008). Although the measured particle diameters agreed within their uncertainties with the precise particle diameters measured by the Multisizer, a bias towards an overestimation of the $10.3 \mu \mathrm{m}$ sized spheres, and worse for the $6.4 \mu \mathrm{m}$ spheres, was observed. This deviation could originate from different sources. The diameters of the spheres were close to, or even below, the resolution of the optical system of $6.8 \mu \mathrm{m}$; diffraction might have caused an enlargement of the detected particle sizes. Also, an inaccurate determination of the longitudinal position of the focus plane would make a particle appear larger than it is. In principle, a more complex algorithm could lower the uncertainty of longitudinal positioning by additionally taking into account the complex amplitude (Pan and Meng, 2003). This should be explored in future versions. Nevertheless, $\mathrm{Pu}$ et al. (2005) also observed an overestimation of small particles sizes in artificial hologram analysis, due to an undersampling of the diffraction pattern in a finite spatial sampling period (that is, the finite pixel size of the camera).

Since Pu et al. (2005) shows that the deviation of the sizing algorithm is of systematic origin, we applied a correction to the size measurements of our algorithm. However, in consideration of our presently incomplete understanding of the sizing deviation, and the fact that the present data represents only three diameters, we used the simplest feasible approach of leaving larger particle diameters $(>12 \mu \mathrm{m})$ uncorrected and assuming a linear dependency of the deviation for smaller diameters (Fig. 5).

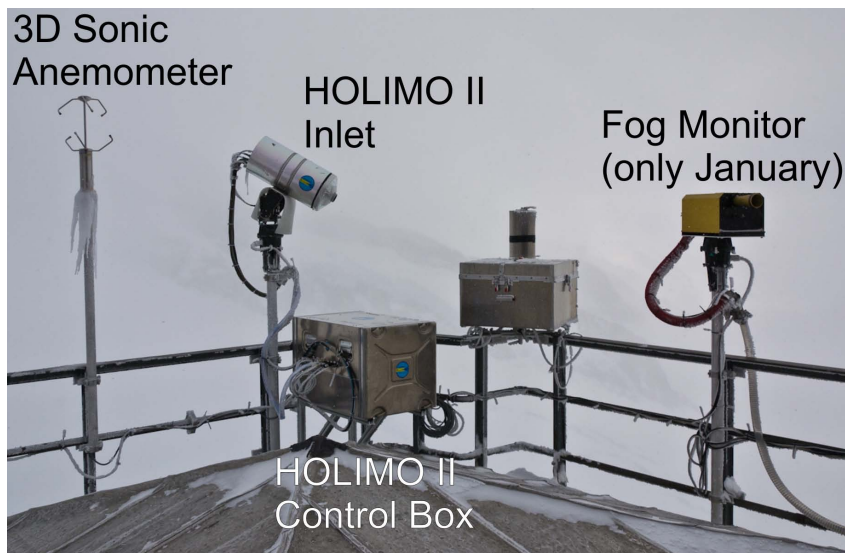

Fig. 6. Experimental setup at the JFJ during the January campaign. The picture faces southeast. Instruments were mounted on posts fastened to the railing on the upper terrace of the Sphinx laboratory. The unlabeled box (second from right) is from a different experiment.

\section{Field measurements}

\subsection{Description of the measurement site}

The field measurements were taken at the high altitude research station Jungfraujoch $\left(\mathrm{JFJ}, 46^{\circ} 33^{\prime} \mathrm{N}, 7^{\circ} 59^{\prime} \mathrm{E}\right.$; annual average pressure $\bar{p}=654.2 \mathrm{hPa}$ ) in the Bernese Alps, Switzerland. The Sphinx laboratory is located at an elevation of 3580 ma.s.l. The data presented in this paper were taken during field campaigns at January and April 2012. In January the instruments were placed on the southeast end of the upper terrace (Fig. 6). At this location the free wind flow was observed to be perturbed by buildings in the western and northern direction.

In April, the instruments were therefore moved to the west end of the lower platform of the Sphinx laboratory. This second sampling location experienced free wind flow from all sides except the east. The ambient wind field and air temperature were measured by a heated 3-D sonic anemometer (THIES CLIMA, Germany) located next to HOLIMO II (Fig. 6). The HOLIMO II inlet was aligned to the ambient wind field by the two axis rotor described in Sect. 2. Data were excluded for the short periods after a wind-direction change where HOLIMO II had not yet been realigned with the wind field. Alignment was defined as $<15^{\circ}$ in the horizontal and $<25^{\circ}$ in the vertical. This also includes the rare cases where wind direction was changing too rapidly to align HOLIMO II with the field.

In addition, during the January campaign a fog monitor (FM-100, DMT, Boulder USA) was measuring beside HOLIMO II and was also placed on a rotating platform (Fig. 6). The fog monitor is a commercially available cloud spectrometer with active inlet sampling (Eugster et al., 2006). It calculates the size and number concentration of cloud 


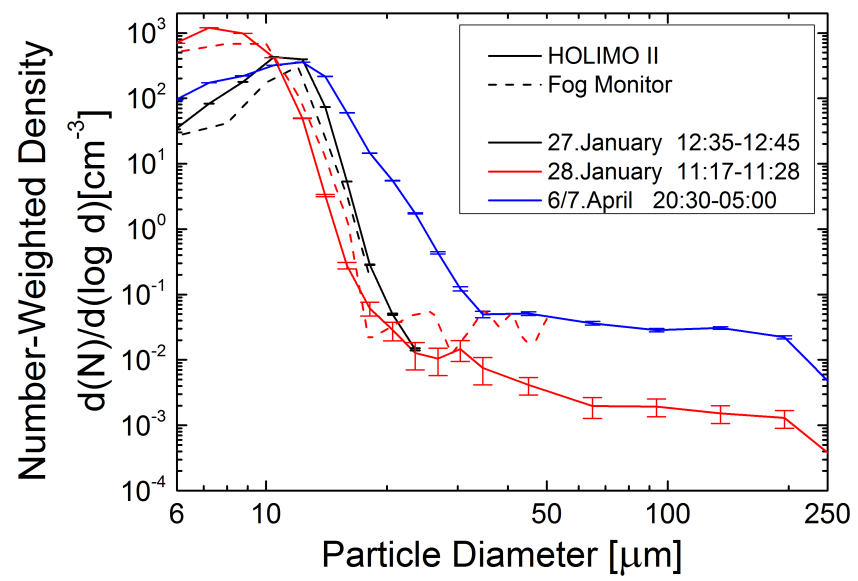

Fig. 7. Cloud particle-number distribution measured by HOLIMO II (solid) and the fog monitor (dashed) during January/April 2012 at Jungfraujoch. The error bars are for one standard deviation, assuming Poisson counting statistics.

particles between 1.5 and $50 \mu \mathrm{m}$ from the measured intensity of forward-scattered light. Particles are assumed to be spherical for the size retrieval, such that aspherical ice particles will usually be undersized (Borrmann et al., 2000).

We present data from two 10 min intervals in January and an eight-hour period in April (see Table 3). The temperature varied between -16 and $-8^{\circ} \mathrm{C}$ and the wind velocity between 2 and $11 \mathrm{~ms}^{-1}$. All cases represent southerly winds and therefore avoid interferences from the surrounding buildings. The air masses therefore likely experienced a moderate ascent over nearby glaciers before reaching the JFJ leading to stratiform clouds at JFJ. The large negative elevation angle (cf. Fig. 6) is a consequence of the location of the Sphinx laboratory, which lies on a peak about $100 \mathrm{~m}$ higher than its surrounding, at the saddle between the Jungfrau and Moench mountains. The elevation angle therefore represents only the local wind conditions.

The April measurements were done in 30 s bursts separated by idle periods of $100 \mathrm{~s}$ to reduce the amount of data to a manageable amount. In this period, $10^{5}$ holograms were recorded, which means that $21.6 \mathrm{~L}$ air was sampled. Over 2.4 million cloud particles between 6 and $250 \mu \mathrm{m}$ were detected.

\subsection{Size distributions of cloud particles}

Size distributions from HOLIMO II measurements are shown in Figs. 7 and 8. The size-corrected (Sect. 3.2) and inletefficiency-corrected (Sect. 2.3) data are shown. For the inletefficiency correction, for the shorter January cases, the mean wind velocity of the entire period was used; for the longer April case, the mean velocity of corresponding $30 \mathrm{~s}$ intervals was used. For particle larger than $20 \mu \mathrm{m}$ the corrected concentration is significantly lower (also shown in Fig. 3c). The number size distribution (Fig. 7) is compared to the fog monitor results.

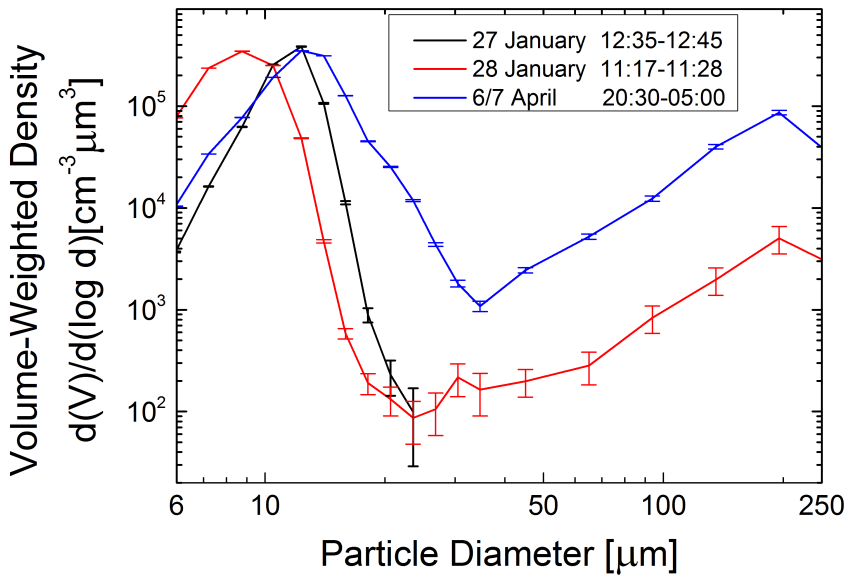

Fig. 8. Cloud-particle volume distributions measured by HOLIMOII during April 2012 at Jungfraujoch. The error bars are for one standard deviation, assuming Poisson counting statistics.

The volume distributions in Fig. 8 show two clear size modes: a smaller mode at $\approx 10 \mu \mathrm{m}$ and a larger one at $\approx 200 \mu \mathrm{m}$. The 27 January case contained only the smaller mode. For all three cases it is reasonable to believe that the smaller $\approx 10 \mu \mathrm{m}$ mode was dominated by liquid droplets, and the larger $\approx 200 \mu \mathrm{m}$ mode by ice crystals.

By manual inspection of the HOLIMO II holograms, it was confirmed that almost all particles between $34 \mu \mathrm{m}$ and $250 \mu \mathrm{m}$ (the HOLIMO II upper sizing limit) were aspherical, and therefore ice crystals. Between $25 \mu \mathrm{m}$ and $34 \mu \mathrm{m}$ a few aspherical particles still existed, but were outnumbered by spherical particles by about three orders of magnitude. These results are in agreement with the observations of McFarquhar et al. (2007). For particles smaller than $25 \mu \mathrm{m}$, the resolution of HOLIMO II is not sufficient to distinguish particle shape. Nevertheless, it is reasonable to assume that spherical particles similarly outnumbered aspherical particles in this range.

Our observation that ice crystals were almost always much larger than water droplets is consistent with the expected rapid growth of ice crystals formed in the presence of water droplets. Due to the lower vapor pressure of ice, a $10 \mu \mathrm{m}$ crystal at water saturation will grow by diffusion to reach $20 \mu \mathrm{m}$ within 10 to $20 \mathrm{~s}$, and $30 \mu \mathrm{m}$ within 25 to $50 \mathrm{~s}$, at temperatures between $-5^{\circ} \mathrm{C}$ and $-30^{\circ} \mathrm{C}$.

During the January period, the number size distributions (Fig. 7) measured by HOLIMO II and the fog monitor agree within an order of magnitude. The shape of the distributions agrees quite well, especially when taking into account that the fog monitor is not well-suited for sub-zero temperatures or ice-crystal (i.e., aspherical-particle) sizing. For the 27 January case, the measurements are similar at sizes larger $10 \mu \mathrm{m}$, but less so for smaller particles where the HOLIMO II sizing is less reliable (Sect. 3.2). Undercounting by the fog monitor may also explain the difference in concentrations. 
Table 3. Summary of three selected measurement periods at JFJ. Air temperature, wind velocity, wind azimuth direction and wind elevation direction were measured by the sonic anemometer. The wind azimuth angle is the meteorological wind direction $\left(0^{\circ}\right.$ is north; $90^{\circ}$ is east). Wind blowing from below has a negative wind elevation angle. Uncertainties are the standard deviation of the specified period.

\begin{tabular}{lccccc}
\hline Time & Temperature & $\begin{array}{c}\text { Wind } \\
\text { velocity } \\
{\left[\mathrm{ms}^{-1}\right]}\end{array}$ & $\begin{array}{c}\text { Wind } \\
\text { azimuth } \\
{\left[{ }^{\circ}\right]}\end{array}$ & $\begin{array}{c}\text { Wind } \\
\text { elevation } \\
{\left[{ }^{\circ}\right]}\end{array}$ \\
\hline 27 Jan 2012 & $12: 35-12: 45$ & $-12.2 \pm 0.3$ & $2.7 \pm 0.7$ & $171 \pm 9$ & $-27 \pm 4$ \\
28 Jan 2012 & $11: 17-11: 28$ & $-15.9 \pm 0.1$ & $9.9 \pm 0.7$ & $151 \pm 5$ & $-39 \pm 2$ \\
6-7 Apr 2012 & 20:50-05:00 & $-8.5 \pm 0.5$ & $3.0 \pm 1.9$ & $194 \pm 7$ & $-24 \pm 13$ \\
\hline
\end{tabular}

For the 28 January case, the HOLIMO II and fog monitor number distributions are again similar for the droplet mode $(10 \mu \mathrm{m})$. For the ice crystal mode $(200 \mu \mathrm{m})$, the HOLIMO II concentrations are lower than the fog monitor concentration. Because the fog monitor is expected to undersize these aspherical crystals, this effect does not explain the discrepancy. Although an imperfect HOLIMO II inlet correction cannot be ruled out, more likely, the difference is due to non-isokinetic sampling of the fog monitor, which was not inlet-efficiency corrected.

\subsection{Development of a mixed-phase cloud}

The development of a mixed-phase cloud was measured in the 6-7 April case study over a period of $8 \mathrm{~h}$ (Fig. 9). For each 30 s interval, the number (Fig. 9a) and volume size distribution (Fig. 9b) were calculated. With an average wind velocity of $3 \mathrm{~m} \mathrm{~s}^{-1}$ the averaging over 30 s translates to a spatial resolution of $90 \mathrm{~m}$, much smaller than that of airborne measurements for a typical flight speed of $100 \mathrm{~m} \mathrm{~s}^{-1}$.

For each interval, the number concentration and water content were calculated. The background caused by resuspension of snow from the ground was investigated by analyzing a cloud free period. The measured background total particle concentration was $0.1 \mathrm{~cm}^{-3}$ and the TWC was $8.3 \mathrm{mg} \mathrm{m}^{-3}$. Because of the extraordinary high wind velocity of $19 \mathrm{~m} \mathrm{~s}^{-1}$ this is an upper estimation and can be expected to be lower for calmer conditions.

The quantiles of these data are shown in Table 4. Because the volume number distribution (Fig. 8) showed a minimum at $34 \mu \mathrm{m}$, the calculations were separated at this size. For the smaller mode, which is dominated by liquid particles, a reasonable water content can be calculated because the maximum in the volume size distribution at around $12 \mu \mathrm{m}$ could be resolved. For the larger mode, the calculation of the water content was associated with additional uncertainty arising from the asphericity and variable density of the ice crystals. Furthermore, ice crystals larger than the $250 \mu \mathrm{m}$ upper limit of the instrument could have contributed significantly to the water content.

The number concentrations of the water droplets $(d<$ $34 \mu \mathrm{m}$ ) showed a mean concentration of $116 \mathrm{~cm}^{-3}$, which is in agreement of the typical value of $100 \mathrm{~cm}^{-3}$ observed for altostratus and altocumulus clouds (Quante, 2004).

Periods without a single ice crystal were measured in the first four hours of the period, while smaller droplets were observed continuously. After 00:00 UTC, the concentrations of ice crystals (defined as $d>34 \mu \mathrm{m}$ ) rose to a mean of $64 \mathrm{~L}^{-1}$, still more than three orders of magnitude less abundant than the cloud droplets. However, the total water content of the larger particles was in the same range as the one of the smaller particles, and between 01:00-02:30 even exceeded it. During this period, the mean water content of the smaller particles was lowered from $0.129 \mathrm{~g} \mathrm{~m}^{-3}$ to $0.067 \mathrm{~g} \mathrm{~m}^{-3}$. This could be an indication that a more aged part of the cloud was measured, where the ice crystals had had more time to grow and deplete some cloud water from the droplets.

Variations in the microphysical properties of the cloud are shown in Table 4, which represents an analysis of 133 intervals during the $8 \mathrm{~h}$ period. The number concentration of water droplets varied between 9 and $350 \mathrm{~cm}^{-3}$. Ice crystal number concentrations up to $200 \mathrm{~L}^{-1}$ were measured, although the median concentration was only $26 \mathrm{~L}^{-1}$. By combining observation from numerous field studies, (DeMott et al., 2010) derived for a temperature of $-8.5^{\circ} \mathrm{C}$ an averaged ice nuclei number concentration of $0.3 \mathrm{~L}^{-1}$. The two order magnitude higher observed ice number concentration indicates that secondary ice formation processes were active.

Some examples of imaged ice crystals are shown in Fig. 9c. In the first three hours, only very few irregular, rather large ice crystals were found, which may have precipitated from higher levels or been resuspended from the ground. Afterwards, a larger number of ice crystals was measured. Besides some irregular crystals, regular crystal habits and aggregates were observed. Some were identifiable as hexagonal plates, some as rectangular columns. Recent aircraftand laboratory-based studies (Bailey and Hallett, 2009; Kuhn et al., 2012) have observed columns and plates as the main habits for temperatures around $-8{ }^{\circ} \mathrm{C}$. 
Table 4. Quantiles of cloud property data from the 6-7 April 2012 case using 30s averages divided into two parts (before and after midnight).

\begin{tabular}{|c|c|c|c|c|c|c|c|c|c|c|c|c|}
\hline & & \multirow{2}{*}{$\begin{array}{l}\text { Date } \\
\text { Quantile }\end{array}$} & \multicolumn{5}{|c|}{6 April 2012} & \multicolumn{5}{|c|}{7 April 2012} \\
\hline & & & $5 \%$ & $25 \%$ & $50 \%$ & $75 \%$ & $95 \%$ & $5 \%$ & $25 \%$ & $50 \%$ & $75 \%$ & $95 \%$ \\
\hline Number concentration & $d<34 \mu \mathrm{m}$ & {$\left[\mathrm{cm}^{-3}\right]$} & 9.2 & 79 & 155 & 256 & 350 & 13 & 41 & 63 & 114 & 203 \\
\hline Number concentration & $d>34 \mu \mathrm{m}$ & {$\left[\mathrm{L}^{-1}\right]$} & 0.0 & 0.0 & 0.0 & 2.7 & 28 & 0.0 & 7.0 & 26 & 88 & 199 \\
\hline Water content & $d<34 \mu \mathrm{m}$ & {$\left[10^{-3} \mathrm{~g} \mathrm{~m}^{-3}\right]$} & 3.2 & 36 & 92 & 204 & 321 & 8.0 & 29 & 53 & 104 & 163 \\
\hline Water content & $d>34 \mu \mathrm{m}$ & {$\left[10^{-3} \mathrm{~g} \mathrm{~m}^{-3}\right]$} & 0.0 & 0.0 & 0.0 & 1.1 & 31 & 0.0 & 4.0 & 31 & 91 & 262 \\
\hline
\end{tabular}

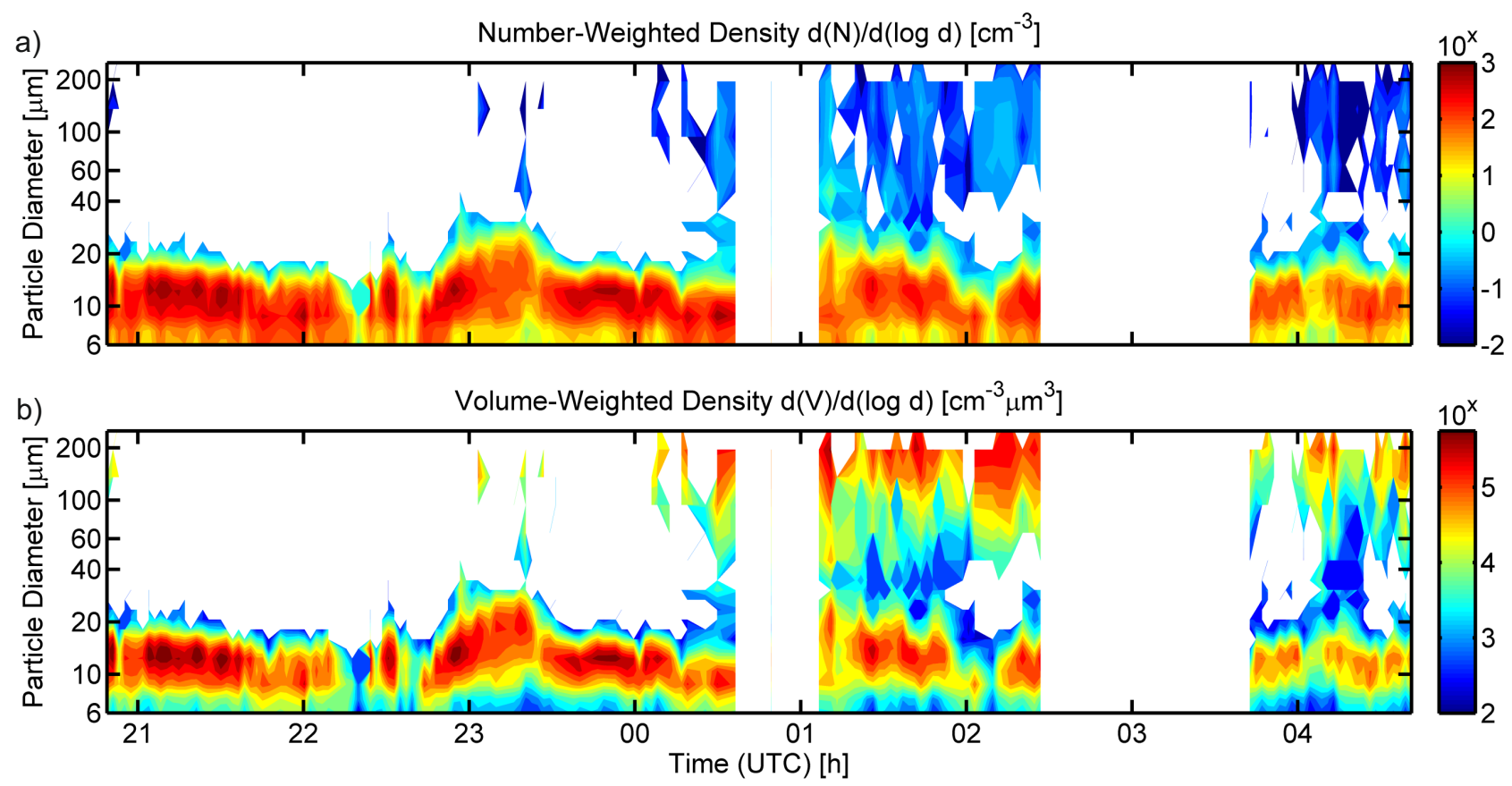

C)

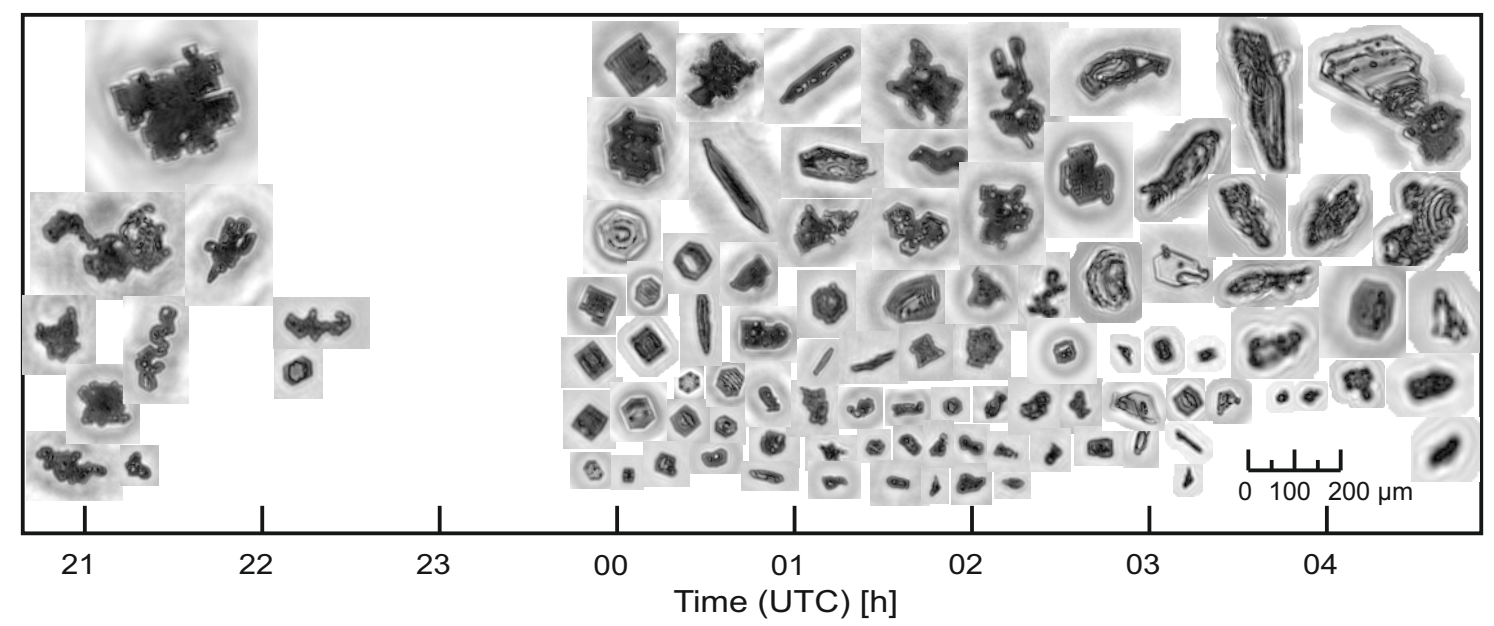

Fig. 9. Time series from the 6-7 April 2012 case measured by HOLIMO II. (a) Cloud particle-number size distribution and (b) volume size distribution. Data gaps are due to icing on the windows. (c) Examples of measured ice particles. 


\section{Conclusions}

In this paper, we introduced the field instrument HOLIMO II, an in situ single cloud particle imager using digital in-line holography. HOLIMO II detects cloud particles between 6 and $250 \mu \mathrm{m}$; computes 2-D images; and calculates the size, concentration, and size distribution of cloud particles. Theoretical restrictions of the optical resolution were discussed and verified experimentally for the HOLIMO II design using a resolution target. Concentration measurements were corrected for inlet biases and verified by numerical simulations.

Single-particle information is revealed by a hologramprocessing algorithm, which includes a size-dependent grouping of particles to prevent the detection of false positives without sacrificing detection volume. The accuracy and precision of the sizing algorithm for small particles were measured using monodisperse spheres. It was confirmed that the algorithm is accurate within the square root of the pixel size, but systematically overestimates particle size close to the detection limit.

The instrument was successfully operated at two field campaigns at the high altitude research station Jungfraujoch, Switzerland, in January and April 2012. Data from three case studies were shown. Below $25 \mu \mathrm{m}$, where water droplets dominated, the measured size distributions agreed well with that of the fog monitor.

Data from three case studies were shown, including a $8 \mathrm{~h}$ period, which is the longest observation of a cloud with an holographic instrument. Two modes were observed, with smaller water droplets and larger ice crystals separated at $34 \mu \mathrm{m}$. In contrast to the liquid water, which was continuously present, intervals without a single larger ice particle were observed within a single cloud.

During the $8 \mathrm{~h}$ period a transition from a liquid to a mixedphase cloud was observed. The mixed-phase cloud was observed for four hours at Jungfraujoch, suggesting that the WBF process, which would have glaciated the cloud, was not yet dominant. Korolev (2007) showed that updraft velocities of around $2 \mathrm{~m} \mathrm{~s}^{-1}$ are sufficient to exceed supersaturation with respect to water, which will result in a growth of both liquid droplets and ice crystals. Such updraft velocities might have occurred during the lifting of the air masses to the JFJ.

Overall, HOLIMO II showed the ability to appropriately measure the microphysical properties of mixed-phase clouds with a high temporal and therefore spatial resolution. Potential future improvements could increase the detection volume using a new optical lens, improving measurement statistics, and extend the detection algorithm to automatically discriminate between liquid droplets and ice crystals by shape.

\section{Appendix A}

\section{Optical resolution considerations}

The resolution was tested using a US Air Force high resolution target (1951 USAF). The target was placed inside the detection volume of the fully assembled instrument (i.e., including windows). The limiting optical resolution is found by identifying the smallest pattern where all three bars in both directions can be resolved. The optical resolution is equal to the distance between two bars in this pattern. The smallest resolvable feature is the width of the bars, which is half the distance between two bars, and thus half the optical resolution.

The achievable optical resolution for a holographic system is limited by three constraints: the numerical aperture imposed by the lens itself $\mathrm{NA}_{\text {lens }}$ (which is a property of the lens design), the resolution limit from the diffraction aspects of in-line holography $\mathrm{NA}_{\text {rec }}$, and the pixel size on the object side $D_{\text {pixel,obj }}$.

The numerical aperture of the optical system NA is a measure of the acceptance angle of the optical system, where wider angles mean higher resolution. For in-line holography a numerical aperture can be approximated by using the reconstruction distance $z_{\text {rec }}$ and an effective aperture $D_{\text {eff }}$, calculated from the geometrical mean of the dimensions of the field of view of the optical system:

$\mathrm{NA}_{\text {rec }} \approx \frac{D_{\text {eff }}}{2 z_{\text {rec }}}$.

$\mathrm{NA}_{\text {rec }}$ describes the limited angle the hologram collects light from and therefore the aperture angle of the reconstruction. The optical resolution $D_{\text {res }}$ can be calculated with the Rayleigh criterion, which describes the smallest circular disk that a system with a numerical aperture NA can distinguish:

$D_{\text {res }}=\frac{1.22 \lambda}{\mathrm{NA}}$,

where $\lambda$ is the laser wavelength.

For HOLIMO II two optical resolutions have to be considered. First, $D_{\text {res,rec }}$ resulting from the limited aperture angle the hologram collects light from; calculated with an effective aperture of $D_{\text {eff }}=\sqrt{4.53 \mathrm{~mm} \times 3.41 \mathrm{~mm}}$. Second, $D_{\text {res,lens }}$ describes the capability of the telecentric lens, with a numerical aperture of $\mathrm{NA}_{\text {lens }}=0.125$, to image holograms onto the camera. The strongest constraint sets the effective limit of the achievable optical resolution of the whole system. Because $D_{\text {res,rec }}$ depends linearly on the reconstruction distances $z$ and $D_{\text {res,lens }}$ is independent of the reconstruction distance $z$, $D_{\text {res,lens }}$ limits the system for small values of $z$ and $D_{\text {res,rec }}$ for large values of $z$.

The third constraint results from the pixel size: at least two pixels are needed to resolve the bar structure on the resolution target. As a consequence, the pixel size on the object side must be at most half the optical resolution to avoid another constraint on the achievable optical resolution. The pixel size 


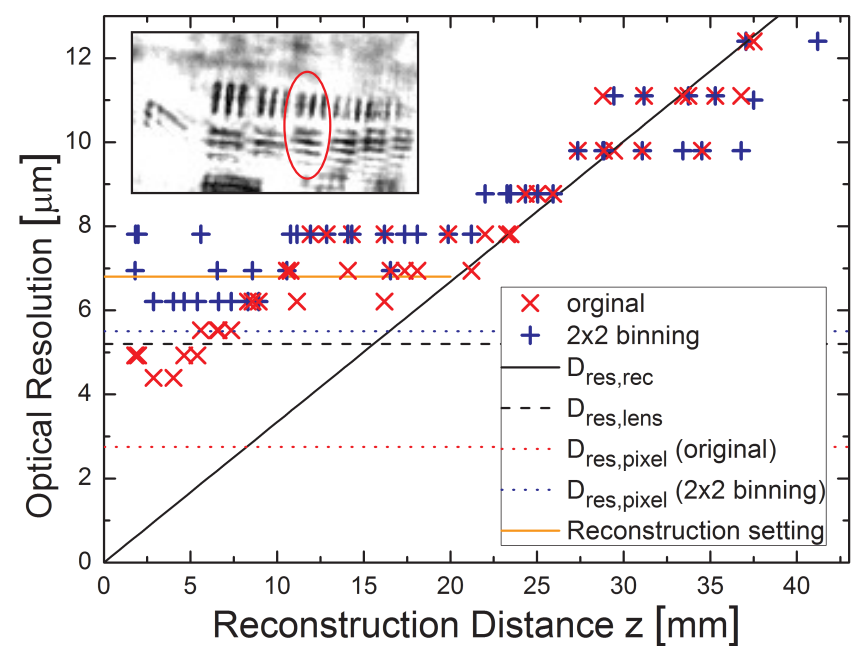

Fig. A1. Graph: measured optical resolutions of reconstructed holograms as a function of target distance. The lines indicate different theoretical optical resolution limits: $D_{\text {res,rec }}$ from the aperture angle of the reconstruction, $D_{\text {res,lens }}$ from the numerical aperture of the lens, and $D_{\text {res,pixel }}$ from the size of the pixels of the original and binned image. The orange line indicates the value the low-pass filter was set to during reconstruction.

on the object side is the camera pixel size $D_{\text {pixel,obj }}$ divided by the magnification $M$ of the lens. Features smaller than this pixel size cannot be resolved reliably. These considerations result in a resolution limit from the pixel size of

$D_{\text {res,pixel }}=\frac{2 \cdot D_{\text {pixel,obj }}}{M}$.

The result of the measured optical resolution as a function of the reconstruction distance $z$ is shown in Fig. A1. The measured optical resolutions are close to these theoretical values.

Unfortunately, the pixel size resolution limit $D_{\text {res,pixel }}=$ $2 \cdot 5.5 \mu \mathrm{m} / 4=2.75 \mu \mathrm{m}$ (red dotted line) is much smaller than the optical resolution limit $D_{\text {res,lens }}=5.2 \mu \mathrm{m}$. Therefore, the optical system is not capable of resolving these small pixels; their presence only lengthens the time needed for reconstruction (Spuler and Fugal, 2011). To speed up the hologram reconstruction time by a factor of about three, we binned $2 \times 2$ pixels together, resulting in a pixel size resolution limit $D_{\text {res,pixel }}=5.5 \mu \mathrm{m}$ (blue dotted line). The binned images (blue crosses) have only a slightly worse optical resolution compared to the original images (red crosses).

Because we wanted to have a constant resolution over the whole detection volume, we only used data from reconstruction distances smaller than $20 \mathrm{~mm}$. To achieve a comparable resolution, and consequently a comparable particle detection, in the whole detection volume we applied a low pass filter to the reconstructed images with the cut off point of $6.8 \mu \mathrm{m}$ (orange line). This is the resolution for a maximum detection distance, where the resolution is worst.
A lens with the same numerical aperture $\left(\mathrm{NA}_{\text {lens }}=0.125\right)$, and therefore the same resolution, and only half the magnification $(2 \times$ instead of $4 \times)$ would increase the detection volume by a factor of eight. The smaller magnification would increase the transversal detection area by a factor of four from $4.53 \mathrm{~mm} \times 3.41 \mathrm{~mm}=15.45 \mathrm{~mm}^{2}$ to $9.06 \mathrm{~mm} \times 6.82 \mathrm{~mm}=$ $61.79 \mathrm{~mm}^{2}$. Additionally, the aperture angle of the reconstruction would approximately double, too, as a consequence of the doubling of the effective aperture $D_{\text {eff }}$. As a result, the maximum reconstruction distance $z$ where an optical resolution of $6.8 \mu \mathrm{m}$ could be achieved would increase from $20 \mathrm{~mm}$ to $40 \mathrm{~mm}$. Unfortunately, such a lens is difficult to construct because it is on the limit which is achievable by spherical optics. To our knowledge, no such lens is currently commercially available, but could be easily integrated into our system in the future.

Acknowledgements. We thank Matthew Beals for his major contribution to the development of the HOLOSUITE software. We thank the International Foundation High Altitude Research Station Jungfraujoch and Gornergrat (HFSJG) for the opportunity to perform experiments on the Jungfraujoch. This work was supported by MeteoSwiss within the Global Atmosphere Watch (GAW) program of the World Meteorological Organization.

Edited by: S. Malinowski

\section{References}

Amsler, P., Stetzer, O., Schnaiter, M., Hesse, E., Benz, S., Moehler, O., and Lohmann, U.: Ice crystal habits from cloud chamber studies obtained by in-line holographic microscopy related to depolarization measurements, Appl. Optics, 48, 58115822, 2009.

Bailey, M. P. and Hallett, J.: A comprehensive habit diagram for atmospheric ice crystals: confirmation from the laboratory, Airs Ii, and other field studies, J. Atmos. Sci., 66, 2888-2899, 2009.

Baron, P. A. and Willeke, K.: Aerosol Measurement: Principles, Techniques, and Applications, John Wiley and Sons, Inc., Hoboken, New Jersey, 2nd Edn., 2005.

Baum, B. A., Heymsfield, A. J., Yang, P., and Bedka, S. T.: Bulk scattering properties for the remote sensing of ice clouds - Part I: Microphysical data and models, J. Appl. Meteorol., 44, 18851895, 2005.

Baumgardner, D., Brenguier, J. L., Bucholtz, A., Coe, H., DeMott, P., Garrett, T. J., Gayet, J. F., Hermann, M., Heymsfield, A., Korolev, A., Kramer, M., Petzold, A., Strapp, W., Pilewskie, P., Taylor, J., Twohy, C., Wendisch, M., Bachalo, W., and Chuang, P.: Airborne instruments to measure atmospheric aerosol particles, clouds and radiation: a Cook's tour of mature and emerging technology, Atmos. Res., 102, 10-29, 2011.

Baumgardner, D., Avallone, L., Bansemer, A., Borrmann, S., Brown, P., Bundke, U., Chuang, P. Y., Cziczo, D., Field, P., Gallagher, M., Gayet, J. F., Heymsfield, A., Korolev, A., Kramer, M., McFarquhar, G., Mertes, S., Mohler, O., Lance, S., Lawson, P., Petters, M. D., Pratt, K., Roberts, G., Rogers, D., Stetzer, O., Stith, J., Strapp, W., Twohy, C., and Wendisch, M.: In situ, 
airborne instrumentatoin: addressing and solving measurement problems in ice clouds, B. Am. Meteorol. Soc., 93, E529-E534, 2012.

Bergeron, T.: On the physics of clouds and precipitation, in: Proces Verbaux de l'Association de Météorologie, 156-178, Int. Union of Geodesy and Geophys., 1935.

Borrmann, S., Luo, B., and Mishchenko, M.: Application of the TMatrix Method to the measurement of aspherical (ellipsoidal) particles with forward scattering optical particle counters, J. Aerosol Sci., 31, 789-799, 2000.

DeMott, P. J., Prenni, A. J., Liu, X., Kreidenweis, S. M., Petters, M. D., Twohy, C. H., Richardson, M. S., Eidhammer, T., and Rogers, D. C.: Predicting global atmospheric ice nuclei distributions and their impacts on climate, P. Natl. Acad. Sci USA, 107, 11217-11222, 2010.

Eugster, W., Burkard, R., Holwerda, F., Scatena, F. N., and Bruijnzeel, L. A.: Characteristics of fog and fogwater fluxes in a Puerto Rican Elfin Cloud Forest, Agr. Forest Meteorol., 139, 288-306, 2006.

Findeisen, W.: Kolloid-Meteorologische Vorgaenge bei Niederschlagsbildung, Meteorol. Z., 55, 121-133, 1938.

Fugal, J. P. and Shaw, R. A.: Cloud particle size distributions measured with an airborne digital in-line holographic instrument, Atmos. Meas. Tech., 2, 259-271, doi:10.5194/amt-2-259-2009, 2009.

Fugal, J. P., Shaw, R. A., Saw, E. W., and Sergeyev, A. V.: Airborne digital holographic system for cloud particle measurements, Appl. Optics, 43, 5987-5995, 2004.

Fugal, J. P., Schulz, T. J., and Shaw, R. A.: Practical methods for automated reconstruction and characterization of particles in digital in-line holograms, Meas. Sci. Technol., 20, 2009.

Garcia-Sucerquia, J., Xu, W., Jericho, S. K., Klages, P., Jericho, M. H., and Kreuzer, H. J.: Digital in-Line Holographic Microscopy, Appl. Optics, 45, 836-850, 2006.

Haralick, R. M. and Shapiro, L. G.: Computer and robot vision, vol. I, Addison-Wesley Pub. Co., Reading, Mass., 1992.

Jericho, S. K., Garcia-Sucerquia, J., Xu, W., Jericho, M. H., and Kreuzer, H. J.: Submersible digital in-Line Holographic Microscope, Rev. Sci. Instrum., 77, 043706-043710, 2006.

Korolev, A.: Limitations of the Wegener-Bergeron-Findeisen Mechanism in the evolution of mixed-phase clouds, J. Aerosol Sci., 64, 3372-3375, 2007.

Kuhn, T., Grishin, I., and Sloan, J. J.: Improved imaging and image analysis system for application to measurement of small ice crystals, J. Atmos. Ocean. Tech., 29, 1811-1824, 2012.
Lan, Y. S. and Lin, C. M.: Design of a relay lens with telecentricity in a holographic recording system, Appl. Optics, 48, 3391-3395, 2009.

Lawson, R. P. and Cormack, R. H.: Theoretical design and preliminary tests of two new particle spectrometers for cloud microphysics research, Atmos. Res., 35, 315-348, 1995.

Liu, B. Y. H., Zhang, Z. Q., and Kuehn, T. H.: A numerical study of interial errors in anisokintec sampling, J. Aerosol Sci., 20, 367380, 1989.

Lu, J., Fugal, J. P., Nordsiek, H., Saw, E. W., Shaw, R. A., and Yang, W.: Lagrangian particle tracking in three dimensions via Single-Camera in-Line Digital Holography, New J. Phys., 10, 125013, doi:10.1088/1367-2630/10/12/125013, 2008.

McFarquhar, G. M., Zhang, G., Poellot, M. R., Kok, G. L., McCoy, R., Tooman, T., Fridlind, A., and Heymsfield, A. J.: Ice properties of single-layer stratocumulus during the Mixed-Phase Arctic Cloud Experiment: 1. observations, J. Geophys. Res.Atmos., 112, 2156-2202, 2007.

Paik, S. and Vincent, J. H.: Aspiration efficiency for thin-walled nozzles facing the wind and for very high velocity ratios, J. Aerosol Sci., 33, 705-720, 2002.

Pan, G. and Meng, H.: Digital holography of particle fields: reconstruction by use of complex amplitude, Appl. Optics, 42, 827833, 2003.

Pu, S. L., Allano, D., Patte-Rouland, B., Malek, M., Lebrun, D., and Cen, K. F.: Particle field characterization by Digital in-Line Holography: 3-D location and sizing, Exp. Fluids, 39, 1-9, 2005.

Quante, M.: The role of clouds in the climate system, J. Phys. IV, 121, 61-86, 2004.

Raupach, S. M. F., Vossing, H. J., Curtius, J., and Borrmann, S.: Digital Crossed-Beam Holography for in situ imaging of atmospheric ice particles, J. Opt. A-Pure Appl. Op., 8, 796-806, 2006.

Shupe, M. D., Daniel, J. S., de Boer, G., Eloranta, E. W., Kollias, P., Long, C. N., Luke, E. P., Turner, D. D., and Verlinde, J.: A focus on mixed-phase clouds: the status of ground-based observational methods, B. Am. Meteorol. Soc., 89, 1549-1562, 2008.

Spuler, S. M. and Fugal, J.: Design of an in-Line, digital holographic imaging system for airborne measurement of clouds, Appl. Optics, 50, 1405-1412, 2011.

Vidaurre, G. and Hallett, J.: Ice and water content of stratiform mixed-phase cloud, Q. J. Roy. Meteorol. Soc., 135, 1292-1306, 2009.

Wegener, A.: Thermodynamik der Atmosphaere, Barth, J. A., Leipzig, 1911. 